\title{
A Introdução de Catalisadores Metalocênicos como Estratégia Competitiva da Indústria de Termoplásticos.
}

\author{
Francisco A. Ribeiro Fo, Maria J osé S. Ferreira Netto e Carlos A. Hemais
}

Resumo: Recentes inovações tecnológicas no setor de polímeros levaram a novos catalisadores que poderão mudar a estrutura de toda a indústria. É feita uma análise das estratégias competitivas adotadas pelas empresas do setor e do impacto que a adoção dos catalisadores metalocênicos vêm causando.

Palavras-chave: Metalocenos, estratégia competitiva, termoplásticos, indústria de polímeros

\section{Introdução}

A tecnologia é uma das principais determinantes da competitividade, e, segundo Porter ${ }^{1}$, mudanças tecnológicas se tornam tanto mais importantes quando afetam a vantagem competitiva da empresa, reduzindo custos ou diferenciando produtos, ou modificam a estrutura da indústria.

O setor de termoplásticos é considerado o mais dinâmico da indústria de polímeros e também o mais produtivo - em 1994 foram produzidas, em termos mundiais, quase 85 milhões de toneladas desses materiais.

A inovação tecnológica no setor de polímeros seguiu uma trajetória de ênfase no aumento de produtividade e novos processos, para preocupação com custos e desperdícios, chegando à fase atual, de diferenciação dos produtos através de grades feitos sob medida para atender às necessidades dos clientes, fazendo com que os termoplásticos, aos poucos, deixem de se enquadrar na categoria das commodities. Neste contexto, novos sistemas catalíticos, com base metalocênica, estão sendo os responsáveis por acele- rar essa transformação tecnológica, que poderá mudar estruturalmente a indústria de polímeros.

$\mathrm{O}$ presente trabalho analisa estrategicamente a competitividade da indústria de termoplásticos e o impacto que a introdução de catalisadores metalocênicos vem causando.

\section{Estratégias competitivas das empresas}

Porter ${ }^{2}$ indicou que a formulação de uma estratégia competitiva implica em dois esforços principais:

- relacionar a empresa ao seu meio ambiente; e

- sistematizar e compatibilizar os recursos internos da empresa (meios) para atingir os objetivos estratégicos escolhidos (fins).

O grau de competitividade em uma indústria depende do conjunto de forças básicas que direcionam a forma e a intensidade dessa competição no segmento industrial específico e exercem forte influência sobre o potencial de crescimento das empresas.

O autor aponta cinco forças competitivas básicas que direcionam a vida das empresas: entrantes 
potenciais, substitutos, fornecedores, compradores e concorrentes. A essas se agregaria uma sexta força, que Teixeira ${ }^{3}$ definiu como aparato político-institucional e, mais recentemente, Hemais ${ }^{4}$ chamou de barreiras governamentais. Estas últimas, através de políticas específicas (reserva de mercado, controle de importações, subsídios às exportações, tributos, taxas de juros, entre outras), podem mudar dramaticamente vantagens competitivas que uma empresa ou o segmento possuem, podendo inibir ou incentivar a lucratividade, a competitividade e o crescimento das empresas.

Existem, ainda, de acordo com Porter ${ }^{2}$, três abordagens genéricas que definem a linha mestra da estratégia adotada pela empresa para enfrentar, de forma potencialmente bem sucedida, os desafios das forças competitivas.
- Liderança no custo total - Visa obter menor custo de produção pela busca de reduções de custo através de melhorias no processo produtivo, domínio total da tecnologia do processo de produção, acesso à matéria-prima pela integração vertical, economias de escala, entre outras;

- Diferenciação - A empresa torna o seu produto diferenciável frente aos substitutos, através de esforços conjuntos de $\mathrm{P} \& \mathrm{D}$, produção e marketing

- Enfoque - A empresa tem por objetivo atingir um alvo estratégico particular, ou seja um nicho de mercado, competindo de maneira mais eficiente que os concorrentes que atuam no mercado.

Kupfer ${ }^{5}$ define a competitividade como a capacidade de uma empresa formular e implementar estratégias que lhe permitam ampliar ou sustentar sua

\section{Tabela 1. Fatores relevantes para a indústria petroquímica/sub-setor de termoplásticos}

\begin{tabular}{|c|c|c|}
\hline Fatores & Tipos & Detalhamento \\
\hline \multirow{3}{*}{ Empresariais } & $\begin{array}{l}\text { Enfase em investimentos de } \\
\text { longo prazo em P\&D }\end{array}$ & $\begin{array}{l}\text { Investimento em } \mathrm{P} \& \mathrm{D} \text {, constante intercâmbio com centros de pesquisas e } \\
\text { universidades e atenção às vantagens tecnológicas advindas de subsidiárias, "joint- } \\
\text { ventures" e licenciamentos }\end{array}$ \\
\hline & Forte orientação para o mercado & $\begin{array}{l}\text { Direcionamento progressivo da empresa para o mercado, no que se refere à } \\
\text { desenvolvimento de novos produtos e consolidação de relação cliente-empresa } \\
\text { pela introdução de inovações tecnológicas }\end{array}$ \\
\hline & $\begin{array}{l}\text { Enfase na produtividade, qua- } \\
\text { lidade e gerência de recursos } \\
\text { humanos }\end{array}$ & $\begin{array}{l}\text { Simplificação das estruturas hierárquicas das empresas e adoção de modelos } \\
\text { gerenciais de incentivo à iniciativa, criatividade e capacidade de decisão }\end{array}$ \\
\hline \multirow{4}{*}{ Estruturais } & Acesso à matéria prima & $\begin{array}{l}\text { Operação de forma integrada, permitindo acesso à matéria-prima e/ou a prática } \\
\text { de preços de transferência }\end{array}$ \\
\hline & Escala de operação & $\begin{array}{l}\text { Economia de escala e economias empresariais são importantes, isto é, deve existir } \\
\text { massa crítica em termos de volume de produção, unidades em operação, } \\
\text { verticalização e diferenciação de produtos, com objetivo de melhor distribuir } \\
\text { custos fixos e investimentos em P\&D }\end{array}$ \\
\hline & $\begin{array}{l}\text { Tamanho e grau de sofisticação } \\
\text { do mercado }\end{array}$ & $\begin{array}{l}\text { Definição de escala de operação é função do tamanho do mercado, havendo } \\
\text { direto relacionamento com custos de produção; esses fatores são } \\
\text { condicionantes da natureza e da dinâmica do desenvolvimento de novos } \\
\text { produtos e aplicações }\end{array}$ \\
\hline & Intercâmbio mundial & $\begin{array}{l}\text { Integração dos mercados internacionais de termoplásticos, devido à } \\
\text { globalização, faz com que os preços sejam regulados pela oferta/demanda em } \\
\text { escala mundial }\end{array}$ \\
\hline \multirow{4}{*}{ Sistêmicos } & Infraestrutura física & $\begin{array}{l}\text { Especialmente no que se refere a energia, transporte (marítimo e rodoviário) e } \\
\text { comunicações }\end{array}$ \\
\hline & Infraestrutura tecnológica & $\begin{array}{l}\text { Representada por universidades, centros de pesquisa, institutos tecnológicos, com } \\
\text { especialização nas áreas de polímeros, catálise, engenharia de processo, etc }\end{array}$ \\
\hline & Políticas macroeconômicas & $\begin{array}{l}\text { Políticas de financiamento (custo de capital, condições de crédito), tributária, } \\
\text { cambial e de comércio exterior, tarifária e de preços }\end{array}$ \\
\hline & Política industrial e tecnológica & $\begin{array}{l}\text { Apoio governamental, incentivos fiscais, subsídios, facilidades para introdução } \\
\text { de novas tecnologias, criação de zonas especiais de processamento industrial, etc }\end{array}$ \\
\hline
\end{tabular}


posição de forma duradoura no mercado. Portanto, a competitividade seria a adequação das estratégias das empresas individuais ao padrão de concorrência, que corresponderiam ao conjunto de fatores críticos de sucesso no mercado em que a empresa se insere. Segundo o autor, esses fatores são os seguintes:

- Empresariais (relacionados à empresa) - estratégia e gestão, capacitação para inovação, capacitação dos recursos humanos, capacitação produtiva;

- Estruturais (relacionados à estrutura industrial) - mercado, configuração da indústria, regime de incentivos e regulação da concorrência;

- Sistêmicos (relacionados ao sistema econômico) - macroeconômicos, infra-estruturais, sociais, político-institucionais, legaisregulatórios e internacionais;

Estes padrões são bem específicos para cada setor industrial e também extremamente dinâmicos, pois sempre estarão em contínua mudança.

Baseando-se nas análises feitas por Kupfer ${ }^{5}$ e por Teixeira $^{3}$, a Tabela 1 apresenta os fatores mais relevantes, a nível mundial, para a indústria petroquímica e dentro desta, o sub-setor de termoplásticos. Esses fatores seriam os responsáveis por definir a competitividade das empresas de polímeros

\section{Termoplásticos}

O sub-setor de termoplásticos (polietileno, polipropileno, PVC, PS e seus respectivos copolímeros) constitui o segmento de mercado mais importante da indústria petroquímica. Essa indústria utiliza como matérias-primas gás natural, nafta, gasóleo para produzir os chamados produtos petroquímicos básicos (ou de primeira geração), que irão para as unidades downstream (ou de segunda geração) gerando produtos intermediários. Esses, por sua vez, serão polimerizados constituindo as resinas termoplásticas. Estas serão processadas pela indústria de transformação (ou de terceira geração) que será responsável pelos produtos finais (filmes, embalagens, perfis, revestimentos, fios e cabos, entre outros).

De um modo geral, essas resinas são consideradas como commodities, visto que são produzidas em grandes quantidades. Entretanto, há tipos para usos mais específicos e sofisticados, que podem ser enquadrados na categoria de especialidades, pois apresentam especificações rígidas e bem diferenciadas, sendo produzidos em pequenas quantidades e tendo preços elevados.

A indústria petroquímica e o sub-setor de termoplásticos, em particular, caracterizam-se por:

- elevado custo dos investimentos;

- grandes economias de escala;

- elevado custo da tecnologia nos últimos anos;

- baixa relação trabalho/capital e pequena participação da mão-de-obra nos custos diretos de produção (a participação das matérias-primas, produtos químicos e catalisadores na produção de termoplásticos situa-se entre $60 \%$ a $70 \%$ dos custos de produção) ${ }^{6}$.

A Figura 1 apresenta como a indústria de termoplásticos se posiciona face às seis forças competitivas apontadas anteriormente.

No que tange a seus fornecedores, a indústria de termoplásticos tem nos produtos petroquímicos básicos (eteno, propeno e benzeno) suas principais matérias-primas, adquiridas de centrais petroquímicas ou de refinarias de petróleo.

Quanto ao mercado consumidor, seja interno ou externo, este é representado pela indústria de transformação, que utiliza os termoplásticos na fabricação de uma ampla variedade de produtos industriais e de bens de consumo, aí incluídos componentes e peças para as indústrias automobilística, eletro-eletrônica, de embalagens bem como utilidades domésticas, tubos e conexões, brinquedos, artigos esportivos, etc.

Já os substitutos compreendem variadas classes de produtos tradicionais (metais, vidros, papel e papelão, madeira, couro, entre outros), que competem com os termoplásticos, que, de uma maneira geral, oferecem sobre eles vantagens significativas em termos de desempenho e de custo.

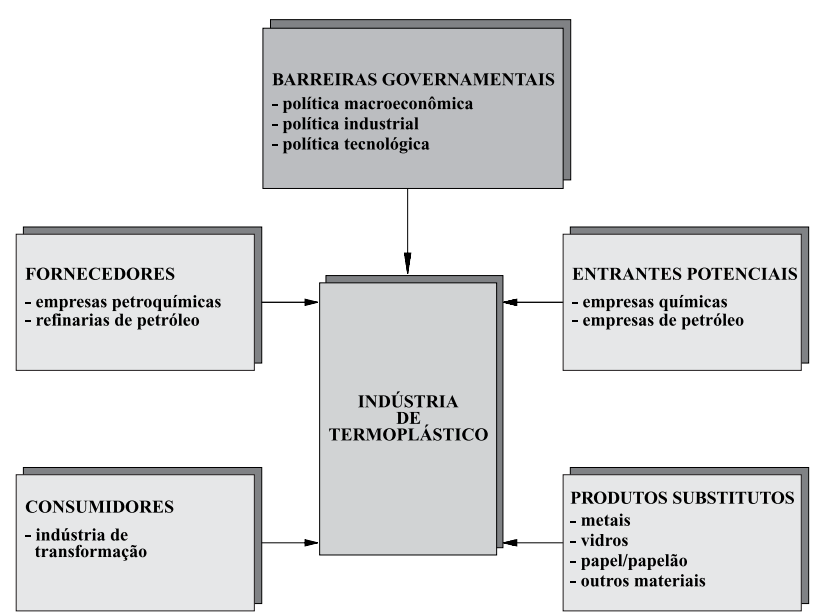

Figura 1. Forças competitivas na indústria de termoplásticos 
Tabela 2. Balanço mundial da indústria de termoplástico em $1994^{7}$

\begin{tabular}{lrrrr}
\hline \multicolumn{1}{c}{ Região } & $\begin{array}{c}\text { Capacidade } \\
\text { Instalada }\end{array}$ & Produção & Consumo & Balanço \\
\hline América do Norte & 29.385 & 26.550 & 24.195 & 2.355 \\
América do Sul & & & & \\
e Central & 4.784 & 3.871 & 3.810 & 61 \\
Argentina & 673 & 513 & 614 & $(101)$ \\
Brasil & 2.790 & 2.490 & 1.986 & 504 \\
Outros & 1.321 & 868 & 1.210 & $(342)$ \\
Europa Ocidental & 25.565 & 21.807 & 21.492 & 315 \\
Europa Oriental & 7.764 & 4.106 & 3.134 & 972 \\
Ásia & 27.534 & 23.162 & 24.231 & $(1.069)$ \\
Oriente Médio & 3.814 & 3.489 & 2.557 & 932 \\
África & 1.008 & 828 & 944 & $(116)$ \\
Oceania & 947 & 701 & 876 & $(175)$ \\
\hline Total & $\mathbf{1 0 0 . 8 0 1}$ & $\mathbf{8 4 . 5 1 4}$ & $\mathbf{8 1 . 2 3 9}$ & $\mathbf{3 . 2 7 5}$ \\
\hline
\end{tabular}

Em relação aos entrantes potenciais, podemos identificá-los em:

- empresas químicas e petroquímicas tradicionais, sejam nacionais ou estrangeiras (multinacionais); incluindo as produtoras de petroquímicos básicos e intermediários;

- empresas da área de petróleo, que visariam integrar-se na fabricação de produtos petroquímicos.

Estas empresas buscam atuar em escala global para ocupar os mercados regionais mais atrativos e/ou assegurar o acesso às matérias-primas estratégicas.

Por fim, a última força competitiva é identificada como barreiras governamentais, que são constituídas das várias políticas e práticas com as quais o Estado se relaciona com as empresas, incluindo tarifas, proteção de setores industriais, subsídios à exportação, restrições ao fluxo de capital, etc., bem como estabelecimento de políticas industrial e tecnológica.

A Tabela 2 apresenta o balanço mundial da indústria de termoplásticos em 1994. A participação do Brasil na oferta foi de $2,95 \%$ (uma produção brasileira de cerca de 2,5 milhões de toneladas face a uma produção mundial de 84,5 milhões de toneladas em 1994). O consumo per capita de termoplásticos em 1994 foi de 13,2 kg/hab no Brasil enquanto nos Estados Unidos foi de 82,2 kg/hab, no Japão 58,7 kg/hab, na França $51,1 \mathrm{~kg} / \mathrm{hab}$ e na Espanha $39,4 \mathrm{~kg} / \mathrm{hab}$.

\section{Inovação tecnológica como estratégia competitiva}

As inovações tecnológicas, que marcaram internacionalmente a indústria de termoplásticos até a década de 70, estavam relacionadas principalmente com o aumento da produtividade das plantas, o desenvolvimento de novos processos e o aprimoramento dos existentes, contribuindo para uma sistemática redução do custo de produção de resinas básicas, ou commodities.

As estratégias competitivas das grandes empresas tinham como linha mestra a liderança no custo total, baseadas nas vantagens competitivas em termos de escala empresarial, escala industrial, nível de operação, custos baixos, domínio da tecnologia, vinculações, canais de distribuição, etc. Estas foram também condicionantes de seus investimentos a nível global (visando o acesso à matéria-prima e energia baratas $)^{8}$.

A partir da crise do petróleo de 1973 e de 1979, as estratégias baseadas em energia e matéria-prima baratas tiveram que ser redefinidas e reestruturadas.

A indústria petroquímica sofreu o impacto da recessão da economia mundial no início dos anos 80 , experimentando, na maior parte da década, uma situação de super-oferta de produtos e baixa rentabilidade. Nos períodos em que se verificavam taxas de crescimento econômico mais elevadas, a alta dos preços das commodities funcionava como mecanismo indutor à realização de novos investimentos. A entrada em operação de novas plantas petroquímicas representava um forte impacto no balanço entre oferta e demanda. $\mathrm{O}$ excesso de oferta e a capacidade instalada ociosa faziam com que os preços caíssem e obrigavam os produtores a buscar mercados alternativos. Desta forma, as exportações se transformaram em um meio de escoamento dos excedentes de produção fazendo com que os preços se situassem pouco acima dos custos variáveis de produção, enquanto que a remuneração dos investimentos era assegurada pelas vendas no mercado interno ${ }^{6}$. Esse quadro que passou a exibir-se de forma periódica pode ser caracterizado como Ciclo Petroquímico.

Com base no novo contexto mundial da globalização da economia, as grandes empresas petroquímicas, visando reduzir sua vulnerabilidade aos ciclos econômicos, iniciaram um amplo programa de reestruturação do setor, que se caracterizou por:

- Racionalização e redução de custos, com a desativação de fábricas, enxugamento de estruturas administrativas e a integração vertical e horizontal dos negócios;

- Redefinição dos objetivos estratégicos das empresas através da canalização de recursos para 
áreas de negócios selecionadas, implicando na diversificação ou na exclusão de produtos e/ ou mercados;

- Diversificação do portfolio de negócios das grandes empresas petroquímicas, via participação nos segmentos de Química Fina e Especialidades, para melhor se protegerem contra as oscilações cíclicas do mercado de commodities;

- Realização de alianças estratégicas visando, entre outros objetivos, a troca de tecnologia e knowhow por determinada posição no mercado ${ }^{(1)}$

- Fusões, aquisições, joint-ventures, licenciamentos, acordos comerciais e alianças diversas para a materialização dos objetivos acima ${ }^{9}$.

As empresas do segmento de termoplásticos, sem perder de vista o aumento da produtividade dos processos e produtos tradicionais (commodities), passaram a enfatizar a sua expansão no mercado de especialidades através de produtos com especificações diferenciadas. Para tanto, a integração da P\&D, desenvolvimento de produto, esforços de marketing, assistência técnica ao consumidor foram fundamentais e decisivas, uma vez que a venda do produto passou a envolver, de modo significante, a agregação de serviços tecnológicos ao consumidor.

Neste novo cenário, a estratégia das grandes empresas de termoplásticos é a de preservar sua posição no mercado de commodities ao mesmo tempo que explora segmentos específicos de mercado (nichos de mercado) de especialidades através de produtos diferenciados.

Observa-se assim, que a expansão a nível internacional dessa indústria direciona-se para a estratégia do enfoque onde custo (pela eficiência do processo produtivo) e diferenciação (qualidade e desempenho) da linha de produtos são fatores importantes à competitividade.

Atualmente no segmento de termoplásticos, os esforços de $\mathrm{P} \& \mathrm{D}$ concentram-se no desenvolvimento de processos tecnológicos voltados para o aprimoramento dos polímeros existentes, com o objetivo de obter-se produtos com melhores propriedades e desempenho superior. Para isso, as grandes empresas produtoras de polímeros já exploram todo um conjunto de opções tecnológicas em termos de catalisadores, tipo e quantidade de comonômeros, projeto de processo (configuração dos reatores, tipo do processo), etc.

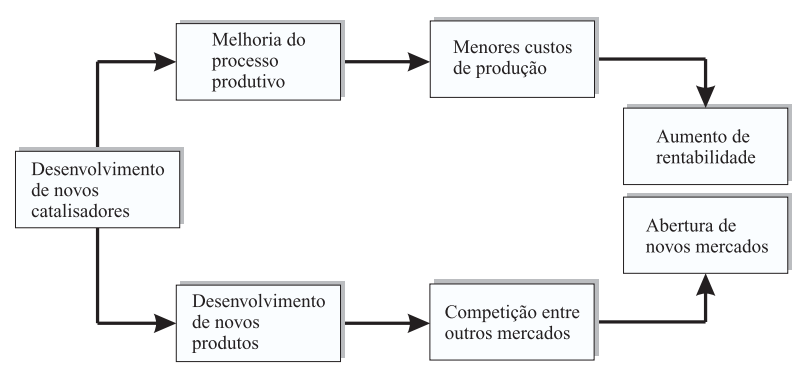

Figura 2. Processo de inovação tecnológica dos termoplásticos Fonte: Adaptado de Silva et al. ${ }^{10}$

Especificamente no caso das poliolefinas (PEe PP), tais avanços tecnológicos se implementados e concretizados, permitirão a esses produtos, seja em commodities ou em especialidades, atender com maior eficiência os mercados existentes e conquistar novos mercados pela substituição de outros polímeros e materiais.

A Figura 2 retrata, de forma esquemática, o processo de inovação tecnológica dos termoplásticos, que está sempre associada à modernização, ao aumento de competitividade através da qualidade e produtividade como instrumentos estratégicos.

\section{0 impacto no mercado dos catalisadores metalocênicos}

Dentre as inovações tecnológicas ocorridas nos últimos anos na indústria de polímeros, a tecnologia baseada em catalisadores metalocênicos é realmente a última geração do ciclo de desenvolvimento de catalisadores para poliolefinas e se constitui em uma revolução tecnológica ao longo dos últimos 60 anos, só comparável à descoberta dos catalisadores de Ziegler-Natta nos anos 5010-11.

A Figura 3 mostra as principais inovações tecnológicas introduzidas na síntese das poliolefinas. Observa-se que é feita distinção entre a revolução tecnológica, que representa a introdução de processo

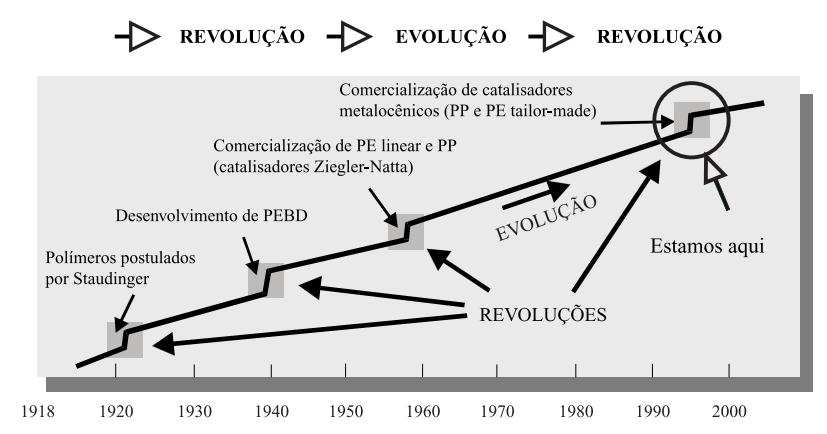

Figura 3. Evolução tecnológica nos processos de produção de poliolefinas ${ }^{12}$

(1) Como exemplos na área de poliolefinas, podem ser citadas as joint-veitures Borealis (Neste e Statoil), Montell (Himont e Shell) e Enichem-Union Carbide 
totalmente novo, gerando, muitas vezes, mudanças radicais na tecnologia, e a evolução tecnológica, que representa o processo incremental de inovação.

Foi desenvolvida uma grande variedade de catalisadores metalocênicos para polimerização de eteno, propeno, $\alpha$-olefinas e outros monômeros por um número de empresas, desencadeando uma corrida sem precedentes para o registro de patentes. As empresas mais ativas são as produtoras de poliolefinas, com investimentos anuais entre US\$500 e US $\$ 600$ milhões, totalizando cerca de US $\$ 3$ bilhões devendo alcançar de US\$7 a US $\$ 10$ bilhões até o ano 2000. Os investimentos equivalem a 70\%-80\% dos gastos totais em $\mathrm{P} \& \mathrm{D}$ de catalisadores, produtos e processos $^{13}$.

\section{Impacto tecnológico}

Há diferenças marcantes na microestrutura dos polímeros produzidos com catalisadores ZieglerNatta metalocênicos comparativamente aos obtidos com catalisadores de Ziegler-Natta convencionais. A Tabela 3 apresenta as principais características dos dois processos de polimerização.

Os catalisadores Ziegler-Natta metalocênicos (single-site catalysts, SSC) têm todos os seus sítios ativos equivalentes em reatividade, comportando-se de modo idêntico durante a polimerização. Isto confere ao polímero obtido uma estreita distribuição de peso molecular e alto grau de uniformidade na estrutura da cadeia polimérica (ramificações e distribuição de comonômero) (Figura 4). Por outro lado, as propriedades físicas (mecânicas, térmicas, elétricas, óticas e reológicas) são melhor definidas, podendo ser controladas de modo preciso com vistas a um melhor desempenho do produto final, permitindo, por sua vez, a modelagem molecular e cinética do polímero para nichos de aplicação.

Os catalisadores metalocênicos podem ser utilizados na polimerização de um número quase ilimitado de monômeros ${ }^{(2)}$, oferecendo, por outro lado, grande versatilidade na formação de copolímeros. Essa característica abre um enorme leque de possibilidades para o desenvolvimento de novos produtos, cobrindo uma faixa de propriedades que vai de polímeros de baixo peso molecular até plásticos de engenharia, passando por elastômeros e plásticos maleáveis (plastômeros) ${ }^{15}$.
Tabela 3. Polímeros obtidos e catalisadores ${ }^{14}$

\begin{tabular}{|c|c|c|}
\hline Características & Ziegler-Natta & Metalocenos \\
\hline Sítios ativos & Múltiplos & Únicos \\
\hline Co-catalisadores & $\begin{array}{l}\text { Alquialuminíos } \\
\text { simples }\end{array}$ & $\begin{array}{l}\text { MAO e ânions não } \\
\text { coordenantes } \\
\text { (NCAs) }\end{array}$ \\
\hline Doadores & Internos e externos & Não necessitam \\
\hline $\begin{array}{l}\text { Distribuição de } \\
\text { Peso Molecular }\end{array}$ & Larga & Estreita \\
\hline $\begin{array}{l}\text { Comprimento das } \\
\text { cadeias }\end{array}$ & Não-uniformes & Uniforme \\
\hline $\begin{array}{l}\text { Distribuição dos } \\
\text { comonômeros }\end{array}$ & Não-uniforme & Uniforme \\
\hline Ponto de fusão & $\begin{array}{l}\text { Independente da } \\
\text { temperatura }\end{array}$ & $\begin{array}{l}\text { Dependente da } \\
\text { temperatura }\end{array}$ \\
\hline Teor de solúveis & Alto & Baixo \\
\hline
\end{tabular}

O elenco dos principais produtos já obtidos com catalisadores metalocênicos compreende vários grades de polietileno (mPE), os polipropilenos isotático (iPP) e sindiotático (sPP), o poliestireno sindiotático (sPS), os copolímeros ciclo-olefínicos (COC), os elastômeros termoplásticos (POEs), os plastômeros poliolefínicos (POPs) ${ }^{16-17}$.

As empresas Dow Chemical e Exxon hoje são importantes produtores comerciais de polietilenos através de catalisadores metalocênicos e a Hoechst tem desenvolvido esses catalisadores para a produção de polipropilenos, com a produção já garantida desses polímeros nos próximos anos. Ainda, a Dow Chemical já está em fase de pre-comercialização de elastômeros poliolefínicos (POE) ${ }^{18-19}$.

Os catalisadores metalocênicos podem ser usados, mediante modificações secundárias, nos processos industriais existentes de polietileno e polipropileno, devendo o crescimento da oferta desses produtos pela nova tecnologia se concretizar, nos próximos anos, basicamente por essa via ${ }^{19}$.

As poliolefinas (PE e PP, tanto homopolímeros como copolímeros) são atualmente os produtos obtidos com catalisadores metalocênicos em estágio mais avançado de desenvolvimento técnico e comercial ${ }^{14}$.

No caso dos polietilenos, o espectro dos produtos obtidos (essencialmente polímeros lineares) cobre a faixa atual de grades comerciais (alta densidade, baixa densidade linear, densidade muito baixa e den-

(2) Os exemplos de patentes indicam mais de 50 monômeros diferentes, muitos deles difíceis ou impossíveis de polimerizar com catalisadores Ziegler-Natta convencionais. 


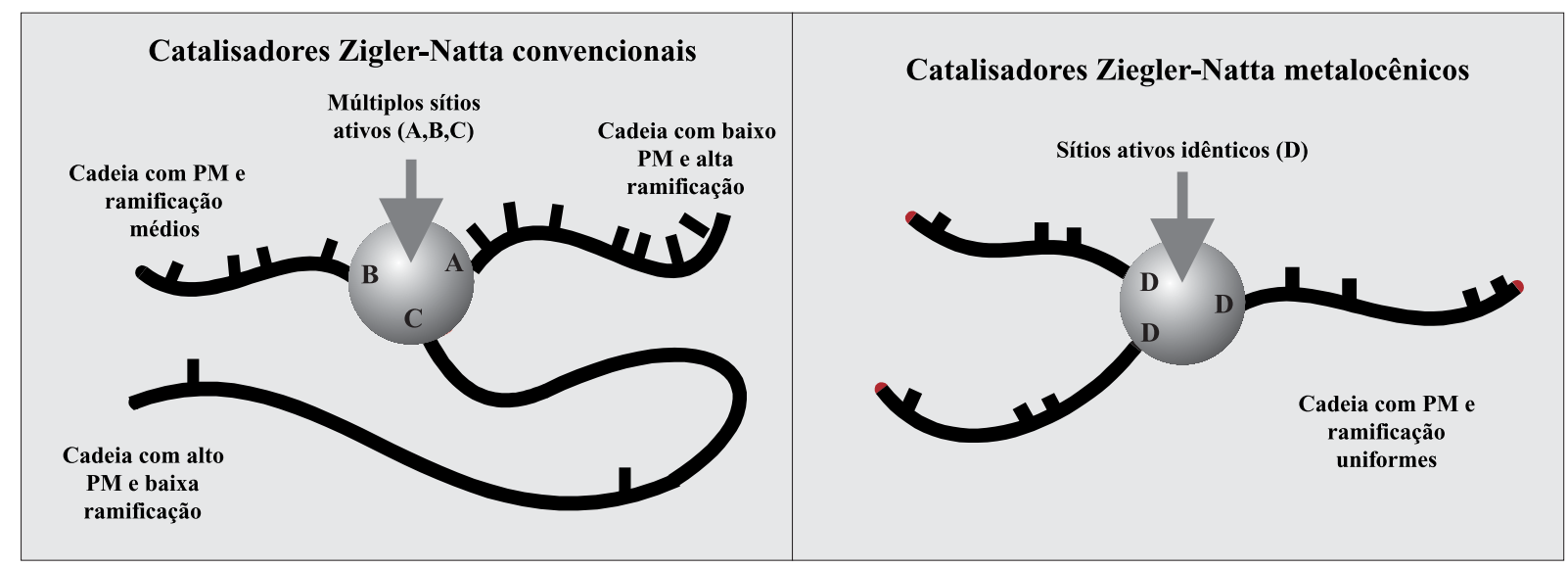

Figura 4. Estrutura das cadeias de polímero ${ }^{14}$

sidade ultra-baixa), assim como plastômeros poliolefínicos (POPs), elastômeros poliolefínicos (POEs) e polímeros de baixo peso molecular. Por suas propriedades superiores, estes produtos já começam a deslocar grades convencionais de polietileno em várias aplicações dos segmentos de commodities e de especialidades, já alcançando mercados servidos atualmente por outros polímeros (EPDM, PVC flexível, EVA, ionômeros e outros) ${ }^{13}$.

$\mathrm{Na}$ produção de polipropilenos, o uso de catalisadores metalocênicos dá origem a dois tipos químicos diferentes: o isotático (iPP) e o sindiotático (sPP). O primeiro inclui tanto copolímeros com alto grau de cristalinidade, que diferem substancialmente do iPP convencional, como homopolímeros que apresentam upgrade de propriedades em relação a este último. Já o sPP, que é superior ao iPP em transparência, flexibilidade e resistência ao impacto, é previsto destinar-se basicamente a aplicações especiais (produtos médicos e embalagens de salgadinhos) em competição com outros polímeros (PVC, PEBD e PEBDL). Os polímeros baseados em catalisadores metalocênicos deverão avançar em substituição a outros materiais, aumentando a versatilidade das resinas de polipropileno ${ }^{17}$.

Além da polimerização, os catalisadores metalocênicos podem ser aplicados a outras reações orgânicas com requisito de estereorregularidade (como exemplo a síntese de compostos quirais usados como fármacos e agroquímicos), assim como em reações de Diels-Alder e na preparação de piridinas substituídas ${ }^{14}$.

Estes aspectos já estão reestruturando a indústria de poliolefinas. Os catalisadores metalocênicos já são empregados na adequação das propriedades físicas a necessidades cada vez mais específicas, aumentando não apenas a utilidade dessas resinas termoplásticas para o mercado mas também a complexidade da indústria pela proliferação de produtos tailor made (sobmedida). As fronteiras entre os diferentes tipos de poliolefinas se tornarão obscuras, com produtos de uma classe (por exemplo, polietilenos lineares) competindo em mercados de substituição com resinas de outra classe, de propriedades similares (por exemplo, polipropilenos maleáveis). Quaisquer combinações possíveis de propriedades serão teoricamente disponíveis e as associações tradicionais propriedade/produto perderão significado. Assim, a indústria de poliolefinas deixará de ser constituída por grupos diferentes de produtos, evoluindo para um conjunto quase ilimitado de materiais poliolefínicos.

\section{Impacto no mercado e na indústria}

Historicamente, os sistemas catalíticos baseados em metalocenos apresentavam custo muito elevado à vista dos alternativos (Ziegler-Natta convencionais e outros), o que, durante bastante tempo, restringiu sua utilização. Entretanto, com as recentes inovações em sua composição química e preparação, a produtividade desses sistemas tem sido progressivamente aumentada, com o seu custo caindo, desde 1988, cerca de $50 \%$ a cada dois anos

Os produtos até aqui fabricados com catalisadores metalocênicos eram todos especialidades de preço elevado, destinadas a aplicações altamente sofisticadas, como a substituição de compostos de PVC flexível em usos médico e alimentício, e ao desenvolvimento de mercados inteiramente novos, não atingidos previamente pelas poliolefinas. No caso dos polietilenos tais produtos estão sendo comercializados na faixa de US $\$ 1,30$ a US $\$ 2,40 / \mathrm{kg}$ (base EUA-1994), portan- 
Tabela 4. Joint ventures e produtos ${ }^{15}$

\begin{tabular}{lc}
\hline \multicolumn{1}{c}{ Empresas } & Produtos \\
\hline Exxon - Mitsui Petrochemical & Polietilenos (fase gasosa) \\
Exxon - Mitsui Petrochemical & Polietilenos (alta pressão) \\
Mitsui Petrochemical - UBE & Polietilenos (fase gasosa) \\
Quantum - Tosoh & Polietilenos \\
Exxon - Hoechst & Polipropileno isotático \\
(bulk) \\
Exxon - DSM \\
Fina - Mitsui Toatsu \\
Potroleum
\end{tabular}

to, bem acima do preço médio de US\$0,70/kg (base EUA-1994) das resinas de PEBD e PEBDL utilizadas em aplicações de grande volume (commodities) ${ }^{15}$.

Embora muitas novas especialidades possam ser esperadas, os catalisadores metalocênicos já começam a ser utilizados na fabricação de resinas de polietileno e polipropileno para aplicações de uso geral, ganhando um mercado significativo mundial desses polímeros já na próxima década.

Os catalisadores metalocênicos estão causando impacto no mercado de poliolefinas de duas formas: deslocando os polímeros similares de seus mercados estabelecidos e criando novos mercados, seja pela substituição de outros tipos de resinas ou através do desenvolvimento de mercados inteiramentes novos.

A utilização potencial de poliolefinas obtidas com catalisadores metalocênicos em mercados de commodities pode ser ilustrada pelo caso de PEBDL, onde os catalisadores metalocênicos permitem eliminar a maioria das limitações de propriedades físicas e processabilidade permitindo a penetração deste polímero em aplicações de grande volume (filmes, revestimentos, etc.) do PEBD-alta pressão.

Por volta de 2005 o mercado mundial de polietilenos estará na casa dos 60 milhões de toneladas. Esse notável aumento não ocorreria sem as resinas baseadas em catalisadores metalocênicos, que estarão contribuindo para o total citado com cerca de
20 milhões de toneladas. Já o mercado mundial de polipropileno situar-se-á, na mesma época, em torno de 35 milhões de toneladas, superior em 5 a 7 milhões de toneladas ao que deveria ocorrer sem a introdução comercial dos catalisadores metalocênicos ${ }^{13}$

Por outro lado, torna-se cada vez mais frequente a ocorrência de acordos entre empresas internacionais para implementação de programas conjuntos de desenvolvimento tecnológico e/ou de mercados de polímeros baseados em catalisadores metalocênicos. Com isso, visam assegurar uma posição sólida em termos de patentes e ao mesmo tempo, aproveitar capacitações existentes em áreas de conhecimento específicas. Algumas dessas associações são indicadas na Tabela 4, com os respectivos produtos em desenvolvimento:

O surgimento de joint-ventures para pesquisar, desenvolver e licenciar tecnologias baseadas em catalisadores metalocênicos já está ocorrendo. Em 1996, a Exxon e a Union Carbide criaram uma nova empresa, na qual cada empresa tem $50 \%$ de participação acionária. Essa empresa está direcionada principalmente para a fabricação de polietileno via catalisador metalocênico ${ }^{21}$. Dow Chemical e Montell, também, formaram uma aliança estratégica para a fabricação de polipropileno via catalisadores metalocênicos, o que mostra que a Dow Chemical já começou a entrar no negócio do polipropileno ${ }^{22}$.

\section{Indústria totalmente integrada através dos catalisadores} Ziegler-Natta metalocênicos

A habilidade dos catalisadores metalocênicos para formar, com alto grau de precisão, moléculas sob medida, adequando o polímero obtido às necessidades de mercado, representa importante inovação no desenvolvimento de novos produtos em comparação ao método tradicional de tentativa-e-erro, baseado fortemente em relações empíricas entre catalisador, processo e polímero. Segundo Forte ${ }^{20}$, com os catalisadores metalocênicos, a capacidade de produzir materiais poliméricos tailor-made, com diferentes estéreo e régio-regularidades, pesos moleculares diversos, diferentes polidispersões, copolímeros e poli(ciclo-olefinas), excede em muito a dos catalisadores Ziegler-Natta convencionais.

Adicionalmente, uma importante ferramenta com que conta hoje a indústria de polímeros para o desenvolvimento de novos materiais é a modelagem molecular baseada em química computacional. Esta técnica faz uso de poderosos e modernos super- 
computadores para simular, através de modelos atômicos e moleculares, tanto polímeros quanto catalisadores, auxiliando no projeto racional desses produtos. Esses modelos dão resultados numéricos que, embora menos confiáveis que os experimentos analíticos, têm precisão suficiente para reduzir em cerca de $90 \%$ o números usual de tais experimentos.

A combinação desses dois elementos catalisadores metalocênicos e química computacional - deverá eliminar muitas corridas experimentais de polimerização, com diminuição de custo e encurtamento dos ciclos de desenvolvimento dos produtos. Materiais poliolefínicos com características otimizadas poderão ser produzidos já nos primeiros ensaios, acelerando tremendamente o desenvolvimento de mercado e a comercialização dos novos produtos. Isso, por outro lado, concorrerá para abreviar o tempo de vida de um número crescente de grades existentes no mercado e para o encurtamento dos ciclos de vida dos produtos em geral.

Dentro desse cenário, grandes corporações internacionais, que dispõem dos requisitos necessários em termos de tecnologia de fabricação, catalisador e química computacional, já estão desenvolvendo uma tecnologia de materiais totalmente integrada, ao longo da cadeia monômero-transformador, como base para o futuro negócio de poliolefinas.

Assim, quando uma necessidade de mercado for primeiro percebida, esses produtores usarão sua tecnologia de materiais para selecionar o melhor grade disponível de uma lista de produtos-padrão e projetar, a partir das moléculas conhecidas, um polímero com um ótimo de processabilidade e a desempenho desejado pelo menor custo. O projeto do molde e da parte estrutural estará integrado neste projeto do polímero, por sua vez ligado à tecnologia de fabricação do catalisador metalocênicos, para descobrir o sistema catalítico a ser especialmente formulado para cada processo de polimerização. As propriedades do polímero "sob medida" poderão ser adicionalmente realçadas através de reforço, formação de liga ou quaisquer outros tratamentos para produzir um material que atenda exatamente à necessidade de mercado percebida. O produtor do polímero alcançará, em primeira mão, sucesso com o seu produto, e o cliente, em primeira mão, sucesso com a sua aplicação.

Atualmente não há produção de nenhum polímero via catalisadores metalocênicos no Brasil. Mesmo assim, alguns grupos de pesquisa universitários têm desenvolvido trabalhos em síntese de catalisadores metalocênicos com resultados bastante satisfatórios ${ }^{(3)}$. Paralelamente, uma estratégia comercial já começa a ser desenvolvida pelos produtores nacionais de PEBDL. Este é importado e, juntamente com os transformadores, uma parceria é estabelecida visando conquistar mercados inteiramente novos ou deslocar polímeros similares de seus mercados estabelecidos

\section{Conclusões}

As empresas de polímeros buscam afirmar-se em um cenário de crescente globalização dos negócios, conjugado à abertura de mercados. Como sobreviver e ser bem sucedidas nestes novos mercados altamente competitivos? Qual o papel que as empresas reservaram às inovações tecnológicas como meio de enfrentar este novo ambiente competitivo?

A concorrência entre as empresas se intensificou fortemente nos últimos anos em função da globalização e regionalização dos mercados, há cada vez mais necessidade de respostas rápidas e eficazes às situações adversas. Quanto mais inovadora for uma empresa, maior será sua capacidade de sobrevivência a longo prazo. A inovação tecnológica utiliza cada vez mais abordagens interligando elementos econômicos e sociais, articulando contribuições da economia evolucionária, da teoria organizacional e administrativa e da teoria sócio-histórica da inovação focalizando as interligações entre o desenvolvimento técnico-científico, sua estrutura organizacional e seu ambiente externo. A estratégia tecnológica é vista como a combinação das capacitações empresariais, organizacionais e tecnológicas com as oportunidades de mercado.

A evolução contínua da tecnologia de processos e produtos depende da eficiência de múltiplos mecanismos de interação tanto no interior da empresa (P\&D, produção, marketing, assistência técnica) como em parcerias técnicas entre centros de pesquisas, universidades, produtores, transformadores e consumidores.

Com o advento dos catalisadores metalocênicos, os produtores de polímeros (PE, PP, elastômeros termoplásticos, etc.) devem estar aptos para transformar seu intenso e intermitente trabalho de P\&D que

\footnotetext{
(3) Como exemplo dessas atividades de pesquisa, cita-se o Grupo de Catálise do IMA/UFRJ, sob a coordenação da Professora Fernanda Coutinho, que já conta com uma considerável quantidade de trabalhos desenvolvidos no assunto
} 
realizam em produtos e aplicações com propriedades e desempenhos superiores, continuar na busca de novas aplicações e mercados e sobretudo serem muito mais rápidos em responder às necessidades do mercado.

O desenvolvimento acelerado de produto e de mercado estabelecerá rápida defasagem competitiva entre as empresas que utilizarem essas novas tecnologias e as que não o fizerem. Os retardatários serão expulsos dos mercados mais nobres, não tendo outra alternativa senão produzir as commodities de maior volume e de menor margem, competindo intensamente entre si na base exclusiva de custo. Julga-se, por isso, que haverá na área de poliolefinas uma proliferação de joint-ventures e de alianças tecnológicas entre licenciadores, produtores e clientes, cada um contribuindo com um elemento-chave para a busca da tecnologia ideal e dinâmica .

A capacidade de inovação tecnológica amplia-se a cada dia diante das inúmeras possibilidades de acrescentar-se novos enfoques às antigas descobertas e também na maneira de encontrar uma via diversa e complementar para novas estratégias competitivas.

\section{Bibliografia}

1.Porter, M.C. (1985) Competitive advantage - creating and sustaining superior performance, New York, The Free Press.

2.Porter, M.C. (1980) Competitive strategy, New York, The Free Press.

3.Teixeira, A, F.L.C. (1992) Estudo da competitividade da indústria brasileira: químico, Nota Técnica Inicial do Complexo, Salvador, setembro, 30p.

4.Hemais, C.A. (1997) Overview-Model of international transfer of technology: a theoretical approach, Technology Management, 3 (3), July, 1-15.

5.Kupfer, D.(1995) O referencial da análise, padrões de concorrência, competitividade e fatores determinantes, IEI/UFRJ, Rio de Jáneiro, publicação interna, 52 p.

6.FUNCEX (1994) Diagnósticos e perspectivas da indústria brasileira de termoplásticos, Fundação Centro de Estudos do Comércio Exterior, São Paulo, 34 p.

7.Silva, Eduardo F. (1995) Polímeros: aspectos mercadológicos e economia de produção, conferência realizada no IMA/UFRJ em 9 de novembro.
8.Ferreira Netto, M.J.S. \& Antunes, A.M.S. (1996) Desafios para o setor petroquímico nacional, trabalho apresentado no $6^{\circ}$ Congresso Brasileiro de Petroquímica, Rio de Janeiro, outubro.

9.Ferreira Netto, M.J.S. \& Ribeiro Filho, F.A. (1995), Estratégias competitivas e tecnológicas na indústria de termoplástico, EQ/UFRJ, Rio de Jáneiro, relatório interno, $18 \mathrm{p}$.

10.Silva, Ana Lucia; Coutinho, Fernanda \& Rocha, Marisa (1996) Dinâmica tecnológica ameaça retardatários, Plástico Moderno, abr, 40-45.

11.Forte, M.M.C. \& Miranda, M.S.L. (1995) Metalocenos preparam revoluções nos plásticos, Química \& Derivados, março, 28-34.

12.Wigotsky, V. (1994) Chemical reawakenings, Plastics Engineering, July, 14-17.

13.Wigotsky, V. (1995) Cooperation, collaboration, Plastics Engineering, May, 16-20

14.Chowdhury, J. \& Moore, S. (1993) Polymers by blueprint, Chemical Engineering, April, 34-39.

15.Ribeiro Filho, F.A. (1994) Metalocenos: revolução tecnológica na indústria de polímeros, PETROQUISA, Rio de Jáneiro, publicação interna.

16.Hanh, L.C. \& Coronado, J. (1994) Catálise ordena cadeia molecular, Plástico Moderno, julho, 8-14.

17.Wigotsky, V. (1995) Metallocenes: the next step, Plastics Engineering, July, 20-24.

18.Reade, L. (1995) Metallocenes, European Plastics News, June, 23-27.

19.Forte, M.M.C., Miranda, M.S.L. \& Dupont, J. (1996) Novas resinas produzidas com catalisadores metalocênicos, Polímeros: Ciência e Tecnologia, $\mathrm{Jul} / \mathrm{Set}, 49-60$

20. O Globo (1996) Union Carbide e Exxon anunciam joint venture, Seção Economia e Negócios, 30 de setembro, 29.

21.Bauman, R.J. (1996) The global outlook for polyolefins, Chem Systems, $20^{\text {th }}$ Annual Latin American Seminar, Rio de Janeiro, November 12.

22.Bauman, R.J. (1994) The global outlook for polyolefins, Chem Systems, $20^{\text {th }}$ Annual Latin American Seminar, Rio de Janeiro, November 12 